\title{
HLA alleles measured from COVID-19 patient transcriptomes reveal associations with disease prognosis in a New York cohort
}

\author{
Rene L Warren ${ }^{\text {Corresp., }}{ }^{1}$, Inanc Birol ${ }^{1}$ \\ ${ }^{1}$ Genome Sciences Centre, BC Cancer, Vancouver, CA-BC, Canada \\ Corresponding Author: Rene L Warren \\ Email address: rwarren@bcgsc.ca
}

Background. The Human Leukocyte Antigen (HLA) gene locus plays a fundamental role in human immunity, and it is established that certain HLA alleles are disease determinants. Previously, we have identified prevalent HLA class I and class II alleles, including DPA1*02:02, in two small patient cohorts at the COVID-19 pandemic onset.

Methods. We have since analyzed a larger public patient cohort data ( $n=126$ patients) with controls, associated demographic and clinical data. By combining the predictive power of multiple in silico HLA predictors, we report on HLA-I and HLA-II alleles, along with their associated risk significance.

Results. We observe HLA-II DPA1*02:02 at a higher frequency in the COVID-19 positive cohort (29\%) when compared to the COVID-negative control group (Fisher's exact test [FET] $p=0.0174$ ). Having this allele, however, does not appear to put this cohort's patients at an increased risk of hospitalization. Inspection of COVID-19 disease severity outcomes, including admission to intensive care, reveal nominally significant risk associations with $A^{*} 11: 01$ (FET $p=0.0078$ ) and $C * 04: 01$ (FET $p=0.0087$ ). The association with severe disease outcome is especially evident for patients with $C^{*} 04: 01$, where disease prognosis measured by mechanical ventilation-free days was statistically significant after multiple hypothesis correction (Bonferroni $p=0.0323$ ). While prevalence of some of these alleles falls below statistical significance after Bonferroni correction, COVID-19 patients with HLA-I C*04:01 tend to fare worse overall. This HLA allele may hold potential clinical value. 
1

2

3

4

5

6

7

8

9

10

11

26

27

28

30

\section{HLA alleles measured from COVID-19 patient transcriptomes reveal associations with disease prognosis in a New York cohort}

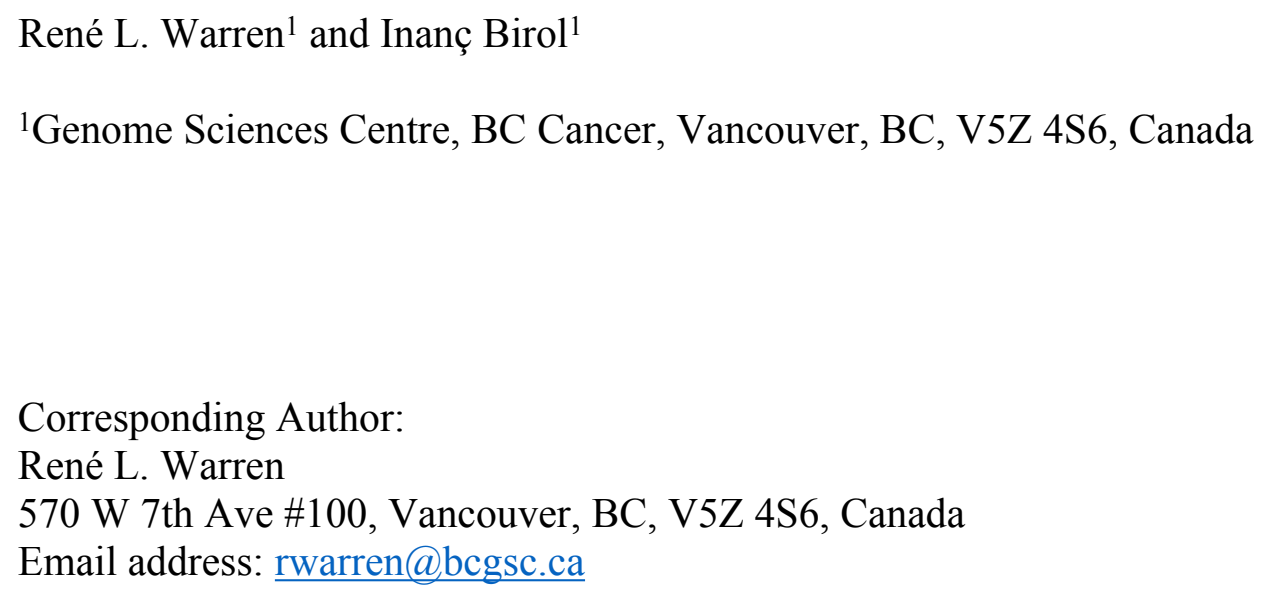




\section{Abstract}

33 Background. The Human Leukocyte Antigen (HLA) gene locus plays a fundamental role in

34 human immunity, and it is established that certain HLA alleles are disease determinants.

35 Previously, we have identified prevalent HLA class I and class II alleles, including DPA1*02:02,

36 in two small patient cohorts at the COVID-19 pandemic onset.

37 Methods. We have since analyzed a larger public patient cohort data ( $\mathrm{n}=126$ patients) with

38 controls, associated demographic and clinical data. By combining the predictive power of

39 multiple in silico HLA predictors, we report on HLA-I and HLA-II alleles, along with their

40 associated risk significance.

41 Results. We observe HLA-II DPA1*02:02 at a higher frequency in the COVID-19 positive

42 cohort (29\%) when compared to the COVID-negative control group (Fisher's exact test [FET]

$43 \mathrm{p}=0.0174)$. Having this allele, however, does not appear to put this cohort's patients at an

44 increased risk of hospitalization. Inspection of COVID-19 disease severity outcomes, including

45 admission to intensive care, reveal nominally significant risk associations with A*11:01 (FET

$46 \mathrm{p}=0.0078)$ and $\mathrm{C}^{*} 04: 01(\mathrm{FET} \mathrm{p}=0.0087)$. The association with severe disease outcome is

47 especially evident for patients with $C^{*} 04: 01$, where disease prognosis measured by mechanical

48 ventilation-free days was statistically significant after multiple hypothesis correction (Bonferroni

$49 \mathrm{p}=0.0323)$. While prevalence of some of these alleles falls below statistical significance after

50 Bonferroni correction, COVID-19 patients with HLA-I C*04:01 tend to fare worse overall. This

51 HLA allele may hold potential clinical value. 


\section{Introduction}

55 Modern history has been plagued by deadly outbreaks, from the recurring influenza (e.g.

56 Spanish, Asian, Hong Kong, Avian) and HIV/AIDS viral pandemics, to bacterial and protist

57 infections causing tuberculosis and malaria. Since the early 2000 s, we have faced another threat:

58 novel coronavirus infections causing severe respiratory illnesses such as SARS, MERS and

59 today, coronavirus disease 2019 - COVID-19 [1]. The SARS-CoV-2 coronavirus responsible for

60 the COVID-19 respiratory disease is of particular concern; not only does SARS-CoV-2 spread

61 quickly, the symptoms of its infection, when exhibited, are very similar to that of the cold and flu

62 making it difficult to diagnose, trace and contain. Further, infections by this virus affects

63 different individuals differently. For instance, older men ( $\geq 65$ years old) with pre-existing

64 medical conditions, such as diabetes, appear at increased risk of progressing into the more severe

65 phase of the disease, yet SARS-CoV-2 infections affect all other age groups evenly except

66 occasionally the children and adolescents [2]. Most peculiar is that a high proportion of

67 individuals who tested positive for SARS-CoV-2 are asymptomatic - as high as $43 \%$ recorded in

68 Iceland, a rate that appears to vary depending on jurisdictions and populations [3-5]. As of now,

69 the disparity in patient response to SARS-CoV-2 infection is still eluding us.

70 The most efficient way to combat pathogens has been through the use of our own defense

71 mechanism: our acquired immunity. This is done by vaccination campaigns that effectively

72 prime our immune systems at the population level before we even encounter pathogens. But

73 design of effective vaccines must consider interactions with host immune genes. The Human

74 Leukocyte Antigens (HLA) are a group of such genes encoding surface receptors that bind short

75 peptide epitopes derived from endogenous (class I) or exogenous (class II) antigens, including 
76 viral antigens, and they facilitate killer or helper $\mathrm{T}$ cells to set off an appropriate immune

77 response. The magnitude of this response varies between patients as populations and individuals

78 have different composition of HLA genes and variable T cell repertoires. As such, HLA induces

79 a bias, which is responsible for documented host susceptibility to disease [6]. Some of the

80 notable associations between HLA and disease are observed in AIDS patients, with certain HLA

81 alleles conferring protection [7]. In other cases, HLA has been implicated with autoimmune

82 diseases and diabetes [8-11]. The exact underlying mechanisms behind these associations are

83 unclear, but there is mounting evidence that bacterial and viral infection may be the trigger for

84 some [10] and that HLA plays a critical role in the viral infection cycle, including viral entry into

85 host cells [12].

86 Since the beginning of the pandemic, worldwide reports have emerged on host

87 susceptibility to COVID-19 [13,14], including reports of possible associations with HLA [15-24]

88 and reports with absence of a definite link in certain populations [25,26]. Using publicly

89 available metatranscriptomic sequencing data made available at the pandemic onset, we had

90 demonstrated the utility of a high throughput in silico method for characterizing the HLA types

91 of COVID-19 patients from bronchoalveolar lavage fluid and blood samples and reported on

92 prevalent alleles, including the DPA1*02:02P - DPB $1 * 05: 01 P$ HLA-II haplotype observed in 7

93 out of the 8 of patients from two small cohorts [21]. Our early report had demonstrated the

94 practical utility of HLA prediction on shotgun sequencing data derived from clinical COVID-19

95 host samples. Here, using public RNA-seq sequencing data from a larger patient cohort of New

96 York patients with $(\mathrm{n}=100)$ and without ( $\mathrm{n}=26)$ COVID-19 and with clinical outcomes and

97 demographics data [27], we report on HLA alleles associated with disease susceptibility 


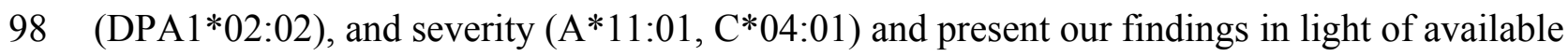

99 demographic characteristics using hospitalization and disease severity metrics. 


\section{Materials \& Methods}

101

102 We downloaded Illumina NOVASEQ-6000 paired-end (50 bp) RNA-Seq reads from libraries

103 prepared from the blood samples of 126 hospitalized New York, NY (USA) patients, with

$104(\mathrm{n}=100)$ or without COVID-19 $(\mathrm{n}=26)$ (ENA project: PRJNA660067, accessions: SRX9033799-

105 SRX9033924). This data is part of a large-scale multi omics study from the Department of

106 Molecular and Cellular Physiology, Albany Medical College, Albany, NY, USA, with aims to

107 analyze COVID-19 Severity. Clinical as well as demographics data was made available by the

108 study authors [27] (GEO accession GSE157103, Additional file 1, Table S1). As per their study,

109 "Patients were considered for enrollment if they were older than 18 years and were admitted to

110 the hospital due to symptoms compatible with COVID-19 infection" and "Patients who tested

111 positive for COVID-19 were later assigned to that specific group and analyzed accordingly, and

112 the COVID-19 negative group was composed of the remaining individuals.”. In their study,

113 patients were tested for COVID-19 by nasopharyngeal swab kit testing using the Abbott

114 Realtime SARS-CoV-2 Assay ${ }^{\circledR}$ (Abbott, IL), as described in a follow-up study that used the

115 same data [28]. We first evaluated the data for consistency (Additional file 2, Figure S1). On

116 each patient RNA-Seq dataset, we ran HLA prediction software OptiType [29] (v1.3.4),

117 seq2HLA [30] (v2.3), and HLAminer [31] (v1.4 targeted assembly mode with defaults) as

118 described [21]. We tallied HLA class I (HLA-I) and class II (HLA-II, supported by Seq2HLA

119 and HLAminer only) allele predictions and for each patient we report the most likely HLA allele

120 (4-digit resolution), indicating HLA predictor tool support (Additional file 1, Tables S2 and

121 S3). For HLA-I predictions, we opted to report the OptiType base predictions with additional

122 support from seq2HLA and HLAminer, when available, due to the former tool's higher

123 predictive performance. Also, because we only had predictions from two tools for HLA-II 
124 alleles and the predictions were generally less reliable, we based the predictions on Seq2HLA,

125 tracking additional support from HLAminer when available. HLA-II alleles with low occurring

126 frequency in the COVID-19 cohort and with no secondary predictions from another tool (e.g.

127 HLA-II DPB1*105:01) were omitted from further analysis.

128 Looking at class I and II alleles predicted in 10\% or more of COVID-19 positive patients

129 (class I, $\mathrm{n}=17$; class II, $\mathrm{n}=25$ ) we calculated Fisher's Exact Test (FET), first testing for

130 enrichment in COVID-19 positive vs. negative patients ( $\mathrm{R}$ function fisher.test, alternative $=$

131 "greater"). We filtered out HLA alleles occurring in less than $10 \%$ of COVID-19 patients to

132 reduce confounding effects due to the small cohort size, while keeping HLA alleles occurring at

133 frequencies expected in heterogeneous populations. For those same alleles (found in $\geq 10 \%$

134 patients) and inspecting only the COVID-19 positive cohort, we tested for the probability of

135 patient hospitalization, as measured by the Intensive Care Unit (ICU) admittance reported by the

136 original study authors, using FET. We looked further into the risk of hospitalization in COVID-

13719 patients with vs. without these alleles using the Kaplan-Meier (KM) estimator (R library

138 survival), plotting the probability of remission using the "hospital-free days post 45 day followup

139 (days)" (HFD-45) metric reported by the study author as a proxy for disease severity, with lower

140 HFD-45 numbers indicating worse outcomes. Similarly, we ran the KM estimator using another

141 metric of disease severity, "ventilator-free days", which captures the most severe cases with

142 COVID-19 patients suffering respiratory deterioration and requiring mechanical ventilation. On

143 each set we calculated the log-rank p-value (R library survminer) and corrected for multiple

144 hypothesis testing (Bonferroni correction) using the number and patient abundance rank of class

145 I $(\mathrm{n}=17)$ or class II $(\mathrm{n}=25)$ HLA alleles observed in $10 \%$ or more of COVID-19 patients. As we

146 predict HLA alleles from each patient, we tally the number of patients with a given allele and 
147 rank the allele by decreasing abundance of patient counts for each allele present in at least 10

148 COVID-19 patients (i.e. $10 \%$ in a cohort of 100 patients) and used those values as the number of

149 hypotheses for further Bonferroni correction of the FET p-values reported herein. We also

150 inspected the combined influence of HLA alleles and patient demographics data (age, sex,

151 ethnicity) on the hospitalization (ICU negative vs. positive) outcomes of COVID-19 patients,

152 using odds-ratio calculations (R function fisher.test, and applying Haldane correction [32] on

153 zero values, when necessary). HLA haplotype association with disease severity was also tested.

154 In all, 861 haplotypes were assessed for higher risk of hospitalization in the Overmyer cohort

155 using the KM estimator, as described above, but none showed significant associations (data not

156 shown). The statistical test employed in our study (Fisher's Exact Tests and log-rank for survival

157 analysis, with Bonferroni corrections based on reported alleles above a minimum threshold) were

158 principled and the underlying data based on fair observations and assumptions. We acknowledge

159 that this study is underpowered due to the small cohort size. 
160 Results

161

162 We collated the HLA class I and class II predictions of three in silico HLA predictors derived

163 from the RNA-seq samples of a recent [27] COVID-19 positive patient cohort $(\mathrm{n}=100)$ with

164 control patients ( $\mathrm{n}=26)$ who tested negative for COVID-19 (Additional file 1, Tables S1-S3).

165 Due to the limiting short read length (paired $50 \mathrm{bp}$ ) we chose to first report on OptiType [29] and

166 seq2HLA [30] class I and class II predictions, and count the additional allele support from

167 seq2HLA and HLAminer [31]. In all, we identify 17 and 25 HLA class I and class II alleles

168 predicted in 10\% or more of COVID-19 patients, respectively (Tables 1 and 2). There were

169 many more alleles predicted (133 and 116 distinct HLA class I and II, respectively), but too few

170 patients are represented at lower cut-offs to compute meaningful statistics. First, we looked at the

171 statistical enrichment (Fisher's Exact Test - FET) of each allele in the COVID-19 positive set,

172 compared to the COVID-19 negative control group. We find HLA-I A*30:02 and HLA-II

173 DPA $1 * 02: 02$ allele enrichment nominally significant $($ FET $p=0.0417$ and $p=0.0174)$ at the

$174 \alpha=0.05$ level (Tables 1 and 2). However, when Bonferroni correction is applied for the number

175 of HLA class I allele tests or when the abundance rank is factored in for $A^{*} 30: 02$, the test is not

176 significant (\#alleles $=17$, Bonferroni $\mathrm{p}=0.7089$; allele abundance rank=12, Bonferroni $\mathrm{p}=$

1770.5004 , respectively). For HLA-II DPA $1 * 02: 02$, Bonferroni correction finds the test insignificant

178 at the $\alpha=0.05$ level for the number of hypothesis and the allele abundance rank (\#alleles $=25$,

179 Bonferroni $\mathrm{p}=0.4350$; allele abundance rank $=4$, Bonferroni $\mathrm{p}=0.0696$ ).

180 COVID-19 positive patients could be further stratified into those who were hospitalized

181 and admitted to the Intensive Care Unit (Tables 1 and 2, ICU+), and those who were not

182 (Tables 1 and 2, ICU-). When computing FET statistics, we find HLA-I A*11:01 and C*04:01

183 significant at the $\alpha=0.05$ level (Table $1 ; p=0.0078$ and $p=0.0087$, respectively) but none 
184 remain significant after Bonferroni correction. Of note, of the 14 COVID-19 patients admitted to

185 ICU who have the HLA-I C*04:01 allele, nine have a Charlson comorbidity index [33] score of

1863 or more (Tables S1 and S2). The Overmyer study authors [27] reported important disease

187 severity metrics (HFD-45 and days without needing mechanical ventilation), which we used to

188 assess the remission probability of COVID-19 patients having a specific allele using Kaplan-

189 Meier estimation. We find patients of the Overmyer cohort with either A*11:01 (Figure 1a) or

$190 \mathrm{C}^{*}$ 04:01 (Figure 1b) to be at a significant increased risk of hospitalization (log-rank $\mathrm{p}=0.0099$

191 and $\mathrm{p}=0.0082$, respectively). When applying multiple test corrections to account for allele

192 abundance rank, only $C^{*} 04: 01(n=5$, Bonferroni $p=0.0410)$ remained significant at the $\alpha=0.05$

193 level. When looking at patients needing mechanical ventilators, a severe outcome in COVID-19

194 disease progression, we only find patients with $C^{*} 04: 01$ to be at a statistically significant

195 increased risk (Figure 1c, $\log$-rank $\mathrm{p}=0.0019)$. Multiple hypothesis test correction retains the

196 statistical significance of this allele when factoring both the number of HLA-I alleles tested

$197(\mathrm{n}=17$, Bonferroni $\mathrm{p}=0.0323)$ and $\mathrm{C}^{*} 04: 01$ abundance rank $(\mathrm{n}=5$, Bonferroni $\mathrm{p}=0.0095)$.

198 Looking at the influence of the aforementioned alleles in combination with simple

199 demographics (sex, age and ethnicity), we find that of the Overmyer cohort patients with the

200 DPA1*02:02 allele, those from a non-minority background and females appear at an increased

201 risk of testing positive for COVID-19 in that cohort (Figure 2 and Additional file 1, Table S4;

202 odds ratio $[\mathrm{OR}]=6.33[5.33-7.34]$, FET $\mathrm{p}=0.0491$ and $\mathrm{OR}=7.33[6.18-8.48]$, FET $\mathrm{p}=0.0326$,

203 respectively, where the numbers in square brackets represent the $95 \%$ confidence interval). The

204 association with gender is also observed in alleles $A^{*} 11: 01$ and $C^{*} 04: 01$, putting female

205 COVID-19 patients of this cohort at an increased risk of hospitalization for the class I alleles

206 (Figure 2 and Additional file 1, Table S4; OR $=12.09$ [10.41-13.76], FET $\mathrm{p}=0.0105$ for 
207 both). In this cohort, we also find patients with $A * 11: 01$ in the younger age group ( $<65$ years

208 old) at increased risk of hospitalization (Figure 2 and Additional file 1, Table S4; OR $=9.54$

209 [8.14-10.94], FET $p=0.0184)$ whereas for those with $C^{*} 04: 01$, it appears a non-minority

210 background and a more advanced age ( $\geq 65$ years old) may be predisposing to ICU

211 hospitalization (Figure 2 and Additional file 1, Table S4; OR $=14.25$ [12.24-16.26], FET p =

2120.0053 and $\mathrm{OR}=9.66[8.27-11.05]$, FET $\mathrm{p}=0.0188$, respectively). 


\section{Discussion}

214

215 We have previously identified the DPA1*02:02 class II allele as being prevalent in two other and

216 independent cohorts, with patients of undisclosed ethnic background, but hospitalized in Wuhan,

217 China [21]. Of populations with reported allele frequencies and an appreciable sampling size

218 ( $\geq 100$ individuals), only Hong Kong Chinese and Japanese have DPA1*02:02 allele frequencies

$219(55.8 \%$ and $43.5 \%$, respectively; [34,35]) above its observed frequency $(29.0 \%)$ in the COVID-

22019 positive cohort analyzed herein. The frequency of this allele in other qualifying populations

221 tends to be generally lower, including in South African (Worcester, 15.6\%), Norwegians

222 (14.0\%), Mexico Chiapas Lacandon Mayans (6.7\%), United Kingdom Europeans (4.3\%) and

223 Spain Navarre Basques (2.2\%). We note that the ethnic background of the Overmyer et al [27]

224 cohort is heterogeneous, and individuals of possible European ancestry represent $45.0 \%$ of the

225 COVID-19 positive cohort and 37.9\% (11/29) of its DPA1*02:02 subset. In contrast, Asians

226 represent only a minority of the cohort $(2.0 \%)$ and its DPA $1 * 02: 02$ subset $3.4 \%(1 / 29)$. It is

227 important to note that, in the Overmyer cohort, DPA1*02:02 is not statistically associated with

228 increased risk of hospitalization. The significant prevalence of this allele in the COVID-19

229 positive vs. negative cohorts (FET $\mathrm{p}=0.0174)$ across all individuals, but also when looking only

230 at females $(\mathrm{FET} \mathrm{p}=0.0326)$ or individuals from a non-minority background $(\mathrm{FET} \mathrm{p}=0.0491)$,

231 and not any other demographics, may prove an important disease marker, which would need to

232 be validated with additional, larger datasets and in independent studies. We also point out that

233 we do not know the relationships, if any, between the New York COVID-19 patients. This is an

234 important consideration and a potential source of bias in genetic association studies worth noting. 
236 they are few. Of note, the association of all aforementioned alleles with narcolepsy [10,11] and a

237 known trigger for this auto-immune disease includes upper-airway infections and influenza

238 vaccinations [36-41]. Susceptibility to narcolepsy may in fact be an indirect effect of HLA class I

239 and the HLA class II DP isotype in response to viral and bacterial infections, including from

240 influenza and streptococcus $[10,36,42,43]$. It has since been reported that HLA-A*11 may be a

241 susceptibility allele to influenza A(H1N1)pdm09 infection in some populations [44] while

242 another report implicates HLA-I allele C*04:01 with high HIV viral loads [45]. Further, it was

243 recently demonstrated that the major histocompatibility complex (MHC) class II DR, DQ and DP

244 isotypes play a role in mediating the cross-species entry of bat influenza viruses in vitro in

245 human/animal cell lines and in mice where engineered MHC-II deficiency made them resistant

246 to upper-respiratory tract infections [12]. It is therefore not a stretch to envision an involvement

247 from these HLA class II isotypes in controlling the cellular entry of a broader range of viral 248 agents in vivo.

249 In a recent study examining HLA susceptibility based on SARS-CoV-2 derived peptide 250 (epitope) binding strengths [46], the HLA-I allele A*11:01 was in silico predicted to bind a large 251 number of SARS-CoV-2 derived peptides $(n=750)$ with varying affinity [IC50 range $4.95-$ 252498.19 , median $=149.62$, mean $=182.28]$, and has been experimentally validated to bind SARS253 CoV-2 peptide GLMWLSYFV (Tables S4 and S7 in Nguyen et al. [46]). In contrast, C*04:01 254 was only predicted in silico to bind six SARS-CoV-2 peptides and at higher IC50 ranges [167.65 $255-469.30$, median $=291.06$, mean $=299.01]($ Table S7 in Nguyen et al. $[46])$ suggesting a more 256 limited ability to present epitopes to T cells and mount an appropriate immune response. 
258 this past year, and on cohorts from many jurisdictions including China [20], Italy [15-17] and the 259 UK [18] among others. Wang et al. [20] compared the HLA allele frequencies between a cohort 260 of 82 Chinese individuals and a control population of bone marrow donors previously studied by 261 the same group. Novelli and co-workers [16] HLA typed a cohort of 99 Italian COVID-19

262 patients, and associated the observed allele frequencies with the HLA types in a reference group 263 of 1,017 Italian individuals also previously studied by the same group. Correale et al. [15] and

264 Pisanti et al. [17] followed a different strategy; these two independent studies leveraged

265 population scale genomics data retrieved from the Italian Bone-Marrow Donors Registry and the 266 National Civil Protection Department. They correlated background HLA allele frequency data 267 with mortality and morbidity rates across Italy to reach at starkly different conclusions on which 268 HLA alleles may play a role in disease etiology and progression. Disagreement between these

269 two studies (also distinct from the results of the other Italian study by Novelli et al.) highlight the 270 importance of large cohorts with matched samples to infer the patient HLA alleles with better

271 statistical significance. Poulton et al. [18] characterized the HLA types of 80 COVID-19 patients 272 in the UK on waiting lists for transplantation, and analyzed observed allele frequencies in 273 comparison to a cohort of 10,000 deceased organ donors and a separate cohort of 308 SARS274 CoV-2-negative individuals also on waiting lists for transplantation, the latter representing a 275 matched demographics for the COVID-19 patients in their cohort. Interestingly, this is the only 276 study that had any overlap between the alleles they flagged and the lists published by other 277 studies cited above. Not surprisingly, the alleles they listed do not intersect with the alleles 278 identified and presented herein and the three alleles we published earlier on a very small group of 279 only eight patients. It is nonetheless intriguing to find little to no HLA allele overlap between 
280 these reports, including with those associated with the 2003 SARS outbreak, a related respiratory

281 disease caused by a similar coronavirus $[13,47,48]$. This could be explained, at least partially, by

282 geographical differences and varying population allele frequencies in those cohorts, relatively

283 small cohort sizes ( $<100$ patients), differences in experimentation setup and/or other factors,

284 including comorbidity status, that may be acting independently of HLA. We note that, since the

285 beginning of the COVID-19 pandemic several large-scale studies reported no link between HLA 286 and COVID-19 $[14,25,26]$. It is worth noting that the MHC region of the genome is highly

287 polymorphic and gene-dense, and without a direct measure of HLA, genome wide association

288 studies (GWAS) have limitations when it comes to reporting associations in this region [49]. For

289 instance, in the GWAS report from the COVID-19 Host Genetics Initiative [14], the HLA locus

290 was excluded from their analysis due to the heterogeneity in effect size observed between

291 studies. Yet, in two other separate large-scale reports where HLA was directly measured and

292 with appreciable COVID-19 patient cohort sizes from Italian/Spanish $(n>1,000)$ and Israeli (n

$293>72,000)$ populations, the absence of associations including with disease severity, is noteworthy

$294[25,26]$.

295 Since we first reported on our observations [50], a few additional notable HLA

296 association with COVID-19 reports became available [19,22-24]. Of interest, mining the US

297 marrow donor program data bank, Augusto and co-workers uncovered an association between

298 HLA-B*15:01 and asymptomatic SARS-CoV-2 infections [24], which is stronger when

299 haplotyped with HLA-DRB1*04:01. Conversely, the latter HLA class II allele was found

300 strongly associated with more severe COVID-19 disease progression in a cohort from the North

301 East of England [23]. In a study from Germany, Weiner and co-workers [22] HLA typed 233

302 COVID-19 patients from Germany, Spain, and Switzerland and found HLA-I C*04:01 to be 
303 associated with an increased risk of intubation in COVID-19 patients, consistent with our

304 findings. In their preprint, they also present a validation of their observations, using the

305 Overmyer [27] cohort data analyzed herein. The report from Japan looked at the HLA types of

306190 COVID-positive patients, of which 53 had developed severe COVID-19 disease [19], and in

307 their cohort they found HLA-A*11:01:01:01 to be significantly associated with the severe form

308 of the disease. Although we found A*11:01 to be only nominally significantly associated with

309 COVID-19 severity in the New York cohort, perhaps due to the sample size and relatively low

310 allele prevalence, it is clear that with the pandemic rapidly evolving, HLA-COVID-19

311 association patterns (reviewed in [51]) are starting to emerge and are being corroborated by

312 independent studies. 


\section{Conclusions}

314

315 Here, we predict HLA-I and HLA-II alleles from publicly available COVID-19 patient blood

316 RNA-seq samples and identified several putative biomarkers. We had also reported one of these

317 biomarkers, DPA1*02:02, in an earlier study. We postulate that patients with the allele may have

318 an increased susceptibility for COVID-19. Further, other alleles, such as C*04:01, may be

319 prognostic indicators of poor outcome. However, although it is well established that patient HLA

320 profiles play a significant role in the onset and progression of infectious diseases in general, we

321 caution against drawing overreaching conclusions from regional, and often limited, observations

322 as is the case here. We note that recently published studies associating HLA alleles and COVID-

323 19, by and large, disagree in their findings, which is not necessarily unexpected given that HLA

324 frequency varies in different populations and that patient cohorts may or may not be

325 representative samplings of those populations. We also note the absence of associations in larger

326 population-centric cohorts. We expect future studies with larger heterogeneous cohort sizes will

327 help bring a clearer picture and demystify the role of patient HLA profiles, if any, in COVID-19

328 susceptibility and disease outcomes.

329

330

331 Acknowledgments

333 The content of this paper is solely the responsibility of the authors, and does not necessarily

334 represent the official views of the National Institutes of Health or other funding organizations. 


\section{References}

336

337 1. Petersen E, Koopmans M, Go U, Hamer DH, Petrosillo N, Castelli F, Storgaard M, Al Khalili

338 S, Simonsen L. Comparing SARS-CoV-2 with SARS-CoV and influenza pandemics. Lancet

339 Infect Dis. 2020;20:e238-e244.

340

341 2. Guan WJ, Ni ZY, Hu Y, Liang WH, Ou CQ, He JX, Liu L, Shan H, Lei CL, Hui DSC, Du B,

342 Li LJ, Zeng G, Yuen KY, Chen RC, Tang CL, Wang T, Chen PY, Xiang J, Li SY, Wang JL,

343 Liang ZJ, Peng YX, Wei L, Liu Y, Hu YH, Peng P, Wang JM, Liu JY, Chen Z, Li G, Zheng ZJ,

344 Qiu SQ, Luo J, Ye CJ, Zhu SY, Zhong NS; China Medical Treatment Expert Group for Covid-

345 19. Clinical Characteristics of Coronavirus Disease 2019 in China. N Engl J Med.

$346 \quad 2020 ; 382: 1708-20$.

347

348 3. Gudbjartsson DF, Helgason A, Jonsson H, Magnusson OT, Melsted P, Norddahl GL,

349 Saemundsdottir J, Sigurdsson A, Sulem P, Agustsdottir AB, Eiriksdottir B, Fridriksdottir R,

350 Gardarsdottir EE, Georgsson G, Gretarsdottir OS, Gudmundsson KR, Gunnarsdottir TR,

351 Gylfason A, Holm H, Jensson BO, Jonasdottir A, Jonsson F, Josefsdottir KS, Kristjansson T,

352 Magnusdottir DN, le Roux L, Sigmundsdottir G, Sveinbjornsson G, Sveinsdottir KE,

353 Sveinsdottir M, Thorarensen EA, Thorbjornsson B, Löve A, Masson G, Jonsdottir I, Möller AD,

354 Gudnason T, Kristinsson KG, Thorsteinsdottir U, Stefansson K. Spread of SARS-CoV-2 in the

355 Icelandic Population. N Engl J Med. 2020;382:2302-15.

356 
357 4. Mizumoto K, Kagaya K, Zarebski A, Chowell G. Estimating the asymptomatic proportion of

358 coronavirus disease 2019 (COVID-19) cases on board the Diamond Princess cruise ship,

359 Yokohama, Japan, 2020. Euro Surveill. 2020;25:2000180.

360

361 5. Nishiura H, Kobayashi T, Miyama T, Suzuki A, Jung SM, Hayashi K, Kinoshita R, Yang Y,

362 Yuan B, Akhmetzhanov AR, Linton NM. Estimation of the asymptomatic ratio of novel

363 coronavirus infections (COVID-19). Int J Infect Dis. 2020;94:154-5.

364

365 6. Dendrou CA, Petersen J, Rossjohn J, Fugger L. HLA variation and disease. Nat Rev Immunol. $366 \quad 2018 ; 18: 325-39$.

367

368 7. Goulder PJ, Walker BD. HIV and HLA class I: an evolving relationship. Immunity. $3692012 ; 37: 426-40$.

370

371 8. Chu X, Yang M, Song ZJ, Dong Y, Li C, Shen M, Zhu YQ, Song HD, Chen SJ, Chen Z,

372 Huang W. Fine mapping MHC associations in Graves' disease and its clinical subtypes in Han 373 Chinese. J Med Genet. 2018;55:685-92.

374

375 9. Noble JA, Valdes AM, Bugawan TL, Apple RJ, Thomson G, Erlich HA. The HLA class I A 376 locus affects susceptibility to type 1 diabetes. Hum Immunol. 2002;63:657-64.

377

378 10. Ollila HM, Ravel JM, Han F, Faraco J, Lin L, Zheng X, Plazzi G, Dauvilliers Y, Pizza F, 379 Hong SC, Jennum P, Knudsen S, Kornum BR, Dong XS, Yan H, Hong H, Coquillard C, Mahlios 
380 J, Jolanki O, Einen M, Arnulf I, Högl B, Frauscher B, Crowe C, Partinen M, Huang YS, Bourgin

381 P, Vaarala O, Désautels A, Montplaisir J, Mack SJ, Mindrinos M, Fernandez-Vina M, Mignot E.

382 HLA-DPB1 and HLA class I confer risk of and protection from narcolepsy. Am J Hum Genet.

$383 \quad 2015 ; 96: 136-46$.

384

385 11. Tafti M, Lammers GJ, Dauvilliers Y, Overeem S, Mayer G, Nowak J, Pfister C, Dubois V, 386 Eliaou JF, Eberhard HP, Liblau R, Wierzbicka A, Geisler P, Bassetti CL, Mathis J, Lecendreux

387 M, Khatami R, Heinzer R, Haba-Rubio J, Feketeova E, Baumann CR, Kutalik Z, Tiercy JM.

388 Narcolepsy-Associated HLA Class I Alleles Implicate Cell-Mediated Cytotoxicity. Sleep. $389 \quad 2016 ; 39: 581-7$

390

391 12. Karakus U, Thamamongood T, Ciminski K, Ran W, Günther SC, Pohl MO, Eletto D, Jeney

392 C, Hoffmann D, Reiche S, Schinköthe J, Ulrich R, Wiener J, Hayes MGB, Chang MW, Hunziker 393 A, Yángüez E, Aydillo T, Krammer F, Oderbolz J, Meier M, Oxenius A, Halenius A, Zimmer G, 394 Benner C, Hale BG, García-Sastre A, Beer M, Schwemmle M, Stertz S. MHC class II proteins 395 mediate cross-species entry of bat influenza viruses. Nature. 2019;567:109-12.

396

397 13. Ovsyannikova IG, Haralambieva IH, Crooke SN, Poland GA, Kennedy RB. The role of host 398 genetics in the immune response to SARS-CoV-2 and COVID-19 susceptibility and severity. 399 Immunol Rev. 2020;296:205-19.

400

401 14. COVID-19 Host Genetics Initiative. Mapping the human genetic architecture of COVID-19.

402 Nature. 2021; doi: 10.1038/s41586-021-03767-x. Epub ahead of print. PMID: 34237774. 
403

404 15. Correale P, Mutti L, Pentimalli F, Baglio G, Saladino RE, Sileri P, Giordano A. HLA-B*44

405 and C*01 Prevalence Correlates with Covid19 Spreading across Italy. Int J Mol Sci.

$406 \quad 2020 ; 21: 5205$.

407

408 16. Novelli A, Andreani M, Biancolella M, Liberatoscioli L, Passarelli C, Colona VL, Rogliani

409 P, Leonardis F, Campana A, Carsetti R, Andreoni M, Bernardini S, Novelli G, Locatelli F. HLA

410 allele frequencies and susceptibility to COVID-19 in a group of 99 Italian patients. HLA. 2020;

411 doi:10.1111/tan.14047.

412

413 17. Pisanti S, Deelen J, Gallina AM, Caputo M, Citro M, Abate M, Sacchi N, Vecchione C,

414 Martinelli R. Correlation of the two most frequent HLA haplotypes in the Italian population to

415 the differential regional incidence of Covid-19. J Transl Med. 2020;18:352.

416

417 18. Poulton K, Wright P, Hughes P, Savic S, Welberry Smith M, Guiver M, Morton M, van

418 Dellen D, Tholouli E, Wynn R, Clark B. A role for human leucocyte antigens in the

419 susceptibility to SARS-Cov-2 infection observed in transplant patients. Int J Immunogenet.

$420 \quad 2020 ; 47: 324-8$.

421

422 19. Khor SS, Omae Y, Nishida N, Sugiyama M, Kinoshita N, Suzuki T, Suzuki M, Suzuki S,

423 Izumi S, Hojo M, Ohmagari N, Mizokami M, Tokunaga K. HLA-A*11:01:01:01,

424 HLA*C*12:02:02:01-HLA-B*52:01:02:02, age and sex are associated with severity of Japanese 
425 COVID-19 with respiratory failure. medRxiv. 2021; 2021.01.26.21250349; doi:

426 https://doi.org/10.1101/2021.01.26.21250349

427

428

429

20. Wang W, Zhang W, Zhang J, He J, Zhu F. Distribution of HLA allele frequencies in 82

Chinese individuals with coronavirus disease-2019 (COVID-19). HLA. 2020;96:194-6.

431

432

21. Warren RL, Birol I. HLA predictions from the bronchoalveolar lavage fluid and blood 433 samples of eight COVID-19 patients at the pandemic onset. Bioinformatics. 2020;36:5271-3.

22. Weiner J, Suwalski P, Holtgrewe M, Thibeault C, Müller M, Patriki D, Quedenau C, Ulrike

K, Helbig ET, Lippert L, Stubbemann P, Real LM, Sanchez JM, Pineda JA, Fernandez-Fuertes

M, Wang X, Karadeniz Z, Saccomanno J, Doehn J-M, Hübner R-H, Hinzmann B, Salvo M,

Blueher A, Siemann S, Jurisic S, Beer H, Rutishauser J, Wiggli B, Schmid H, Danninger K,

Binder R, Victor CM, Mühlemann B, Braun A, Ripke S, Jones TC, Suttorp N, Witzenrath M,

441 Beule D, Landmesser U, Guettouche T, Kurth F, Heidecker B. HLA-C* 04:01 is a Genetic Risk

442 Allele for Severe Course of COVID-19. medRxiv. 2020; 2020.12.21.20248121; doi:

443 https://doi.org/10.1101/2020.12.21.20248121

23. Langton DJ, Bourke SC, Lie BA, Reiff G, Natu S, Darlay R, Burn J, Echevarria C. The 
448

449

450

451

452

453

454

455

456

457

458

459

460

461

462

463

464

465

466

467

468

469

470

24. Augusto DG, Yusufali T, Peyser ND, Butcher X, Marcus GM, Olgin JE, Pletcher MJ, Maiers

M, Hollenbach JA. HLA-B*15:01 is associated with asymptomatic SARS-CoV-2 infection. medRxiv. 2021;2021.05.13.21257065. doi: 10.1101/2021.05.13.21257065.

25. Severe Covid-19 GWAS Group, Ellinghaus D, Degenhardt F, Bujanda L, Buti M, Albillos A, Invernizzi P, Fernández J, Prati D, Baselli G, Asselta R, Grimsrud MM, Milani C, Aziz F, Kässens J, May S, Wendorff M, Wienbrandt L, Uellendahl-Werth F, Zheng T, Yi X, de Pablo R, Chercoles AG, Palom A, Garcia-Fernandez AE, Rodriguez-Frias F, Zanella A, Bandera A, Protti A, Aghemo A, Lleo A, Biondi A, Caballero-Garralda A, Gori A, Tanck A, Carreras Nolla A, Latiano A, Fracanzani AL, Peschuck A, Julià A, Pesenti A, Voza A, Jiménez D, Mateos B, Nafria Jimenez B, Quereda C, Paccapelo C, Gassner C, Angelini C, Cea C, Solier A, Pestaña D, Muñiz-Diaz E, Sandoval E, Paraboschi EM, Navas E, García Sánchez F, Ceriotti F, MartinelliBoneschi F, Peyvandi F, Blasi F, Téllez L, Blanco-Grau A, Hemmrich-Stanisak G, Grasselli G, Costantino G, Cardamone G, Foti G, Aneli S, Kurihara H, ElAbd H, My I, Galván-Femenia I, Martín J, Erdmann J, Ferrusquía-Acosta J, Garcia-Etxebarria K, Izquierdo-Sanchez L, Bettini LR, Sumoy L, Terranova L, Moreira L, Santoro L, Scudeller L, Mesonero F, Roade L, Rühlemann MC, Schaefer M, Carrabba M, Riveiro-Barciela M, Figuera Basso ME, Valsecchi MG, Hernandez-Tejero M, Acosta-Herrera M, D'Angiò M, Baldini M, Cazzaniga M, Schulzky M, Cecconi M, Wittig M, Ciccarelli M, Rodríguez-Gandía M, Bocciolone M, Miozzo M, Montano N, Braun N, Sacchi N, Martínez N, Özer O, Palmieri O, Faverio P, Preatoni P, Bonfanti P, Omodei P, Tentorio P, Castro P, Rodrigues PM, Blandino Ortiz A, de Cid R, Ferrer R, Gualtierotti R, Nieto R, Goerg S, Badalamenti S, Marsal S, Matullo G, Pelusi S, Juzenas S, Aliberti S, Monzani V, Moreno V, Wesse T, Lenz TL, Pumarola T, Rimoldi V, Bosari S, 
471 Albrecht W, Peter W, Romero-Gómez M, D'Amato M, Duga S, Banales JM, Hov JR, Folseraas

472 T, Valenti L, Franke A, Karlsen TH. Genomewide Association Study of Severe Covid-19 with

473 Respiratory Failure. N Engl J Med. 2020;383:1522-1534.

474

475 26. Ben Shachar S, Barda N, Manor S, Israeli S, Dagan N, Carmi S, Balicer R, Zisser B,

476 Louzoun Y. MHC Haplotyping of SARS-CoV-2 Patients: HLA Subtypes Are Not Associated

477 with the Presence and Severity of COVID-19 in the Israeli Population. J Clin Immunol. 2021;14788.

479

480

27. Overmyer KA, Shishkova E, Miller IJ, Balnis J, Bernstein MN, Peters-Clarke TM, Meyer 481

JG, Quan Q, Muehlbauer LK, Trujillo EA, He Y, Chopra A, Chieng HC, Tiwari A, Judson MA, 482 Paulson B, Brademan DR, Zhu Y, Serrano LR, Linke V, Drake LA, Adam AP, Schwartz BS, 483 Singer HA, Swanson S, Mosher DF, Stewart R, Coon JJ, Jaitovich A. Large-Scale Multi-omic 484 Analysis of COVID-19 Severity. Cell Syst. 2020; doi:10.1016/j.cels.2020.10.003. 485

28. Balnis J, Madrid A, Hogan KJ, Drake LA, Chieng HC, Tiwari A, Vincent CE, Chopra A, 487 Vincent PA, Robek MD, Singer HA, Alisch RS, Jaitovich A. Blood DNA methylation and 488 COVID-19 outcomes. Clin Epigenetics. 2021;13:118.

29. Szolek A, Schubert B, Mohr C, Sturm M, Feldhahn M, Kohlbacher O. OptiType: precision HLA typing from next-generation sequencing data. Bioinformatics. 2014;30:3310-6. 492 
493 30. Boegel S, Löwer M, Schäfer M, Bukur T, de Graaf J, Boisguérin V, Türeci O, Diken M,

494 Castle JC, Sahin U. HLA typing from RNA-Seq sequence reads. Genome Med. 2012;4:102.

495

496 31. Warren RL, Choe G, Freeman DJ, Castellarin M, Munro S, Moore R, Holt RA. Derivation of 497 HLA types from shotgun sequence datasets. Genome Med. 2012;4:95.

498

499

32. Valenzuela, C. Dos soluciones para la estimación de "odds ratios" con ceros [2 solutions for 500 estimating odds ratios with zeros]. Rev Med Chil. 1993;121:1441-4.

501

502 33. Charlson ME, Pompei P, Ales KL, MacKenzie CR. A new method of classifying prognostic 503 comorbidity in longitudinal studies: development and validation. J Chronic Dis. 1987;40:373-83. 504

34. Gonzalez-Galarza FF, McCabe A, Santos EJMD, Jones J, Takeshita L, Ortega-Rivera ND, 506 Cid-Pavon GMD, Ramsbottom K, Ghattaoraya G, Alfirevic A, Middleton D, Jones AR. Allele 507 frequency net database (AFND) 2020 update: gold-standard data classification, open access 508 genotype data and new query tools. Nucleic Acid Research. 2020;48:D783-8.

510 35. Allele frequency net database. http://allelefrequencies.net/

511

512 36. Han F, Lin L, Warby SC, Faraco J, Li J, Dong SX, An P, Zhao L, Wang LH, Li QY, Yan H,

513 Gao ZC, Yuan Y, Strohl KP, Mignot E. Narcolepsy onset is seasonal and increased following the 5142009 H1N1 pandemic in China. Ann Neurol. 2011;70:410-7. 
516 37. Han F, Faraco J, Dong XS, Ollila HM, Lin L, Li J, An P, Wang S, Jiang KW, Gao ZC, Zhao

517 L, Yan H, Liu YN, Li QH, Zhang XZ, Hu Y, Wang JY, Lu YH, Lu CJ, Zhou W, Hallmayer J,

518 Huang YS, Strohl KP, Pollmächer T, Mignot E. Genome wide analysis of narcolepsy in China

519 implicates novel immune loci and reveals changes in association prior to versus after the 2009

520 H1N1 influenza pandemic. PLoS Genet. 2013;9:e1003880.

521

522 38. Heier MS, Gautvik KM, Wannag E, Bronder KH, Midtlyng E, Kamaleri Y, Storsaeter J.

523 Incidence of narcolepsy in Norwegian children and adolescents after vaccination against H1N1

524 influenza A. Sleep Med. 2013;14:867-71.

525

526 39. Moss AJ, Gaughran FP, Karasu A, Gilbert AS, Mann AJ, Gelder CM, Oxford JS, Stephens

527 HA, Lambkin-Williams R. Correlation between human leukocyte antigen class II alleles and

528 HAI titers detected post-influenza vaccination. PLoS One. 2013;8:e71376.

529

530 40. Montplaisir J, Petit D, Quinn MJ, Ouakki M, Deceuninck G, Desautels A, Mignot E, De

531 Wals P. Risk of narcolepsy associated with inactivated adjuvanted (AS03) A/H1N1 (2009)

532 pandemic influenza vaccine in Quebec. PLoS One. 2014;9:e108489.

533

534 41. Wijnans L, Lecomte C, de Vries C, Weibel D, Sammon C, Hviid A, Svanström H, Mølgaard-

535 Nielsen D, Heijbel H, Dahlström LA, Hallgren J, Sparen P, Jennum P, Mosseveld M, Schuemie

536 M, van der Maas N, Partinen M, Romio S, Trotta F, Santuccio C, Menna A, Plazzi G,

537 Moghadam KK, Ferro S, Lammers GJ, Overeem S, Johansen K, Kramarz P, Bonhoeffer J, 
538 Sturkenboom MC. The incidence of narcolepsy in Europe: before, during, and after the influenza

539 A(H1N1)pdm09 pandemic and vaccination campaigns. Vaccine. 2013;31:1246-54.

540

541 42. Aran A, Lin L, Nevsimalova S, Plazzi G, Hong SC, Weiner K, Zeitzer J, Mignot E. Elevated 542 anti-streptococcal antibodies in patients with recent narcolepsy onset. Sleep. 2009;32:979-83.

544 43. Mahlios J, De la Herrán-Arita AK, Mignot E. The autoimmune basis of narcolepsy. Curr 545 Opin Neurobiol. 2013;23:767-73.

546

547 44. Dutta M, Dutta P, Medhi S, Borkakoty B, Biswas D. Polymorphism of HLA class I and class 548 II alleles in influenza A(H1N1)pdm09 virus infected population of Assam, Northeast India. J 549 Med Virol. 2018;90:854-60.

550

551 45. Olvera A, Pérez-Álvarez S, Ibarrondo J, Ganoza C, Lama JR, Lucchetti A, Cate S,

552 Hildebrand W, Bernard N, Gomez L, Sanchez J, Brander C. The HLA-C*04: 01/KIR2DS4 gene 553 combination and human leukocyte antigen alleles with high population frequency drive rate of 554 HIV disease progression. AIDS. 2015;29:507-17.

556 46. Nguyen A, David JK, Maden SK, Wood MA, Weeder BR, Nellore A, Thompson RF. Human 557 Leukocyte Antigen Susceptibility Map for Severe Acute Respiratory Syndrome Coronavirus 2. J 558 Virol. 2020;94:e00510-20. 
560 47. Lin M, Tseng HK, Trejaut JA, Lee HL, Loo JH, Chu CC, Chen PJ, Su YW, Lim KH, Tsai

561 ZU, Lin RY, Lin RS, Huang CH. Association of HLA class I with severe acute respiratory

562 syndrome coronavirus infection. BMC Med Genet. 2003;4:9.

563

564 48. Sanchez-Mazas A. HLA studies in the context of coronavirus outbreaks. Swiss Med Wkly. $5652020 ; 150: w 20248$.

566

567 49. Kennedy AE, Ozbek U, Dorak MT. What has GWAS done for HLA and disease

568 associations? Int J Immunogenet. 2017;44:195-211.

569

570 50. Warren RL, Birol I. Retrospective in silico HLA predictions from COVID-

57119 patients reveal alleles associated with disease prognosis. medRxiv. 2020;

572 2020.10.27.20220863; doi: https://doi.org/10.1101/2020.10.27.20220863

573

574 51. Migliorini F, Torsiello E, Spiezia F, Oliva F, Tingart M, Maffulli N. Association between

575 HLA genotypes and COVID-19 susceptibility, severity and progression: a comprehensive review 576 of the literature. Eur J Med Res. 2021;26:84. 


\section{Figure 1}

HLA alleles associated with higher risk of hospitalization in a COVID-19 positive patient cohort.

COVID-19 positive patients were split into two groups per allele tested, depending on whether they were predicted to have the HLA allele under scrutiny or not. We ran the KaplanMeier estimator (R package survival) using the Overmyer et al. cohort [27] HFD-45 metric for estimating the remission probability of patients without or with alleles (a) $A^{*} 11: 01$ or (b) $C * 04: 01$ and mechanical ventilator-free days to estimate the statistical significance of the more severe disease outcome observed in COVID-19 patients with (c) C*04:01. Log-rank $p$ values were calculated for each ( $\mathrm{R}$ package survminer) and are indicated on the plots. 

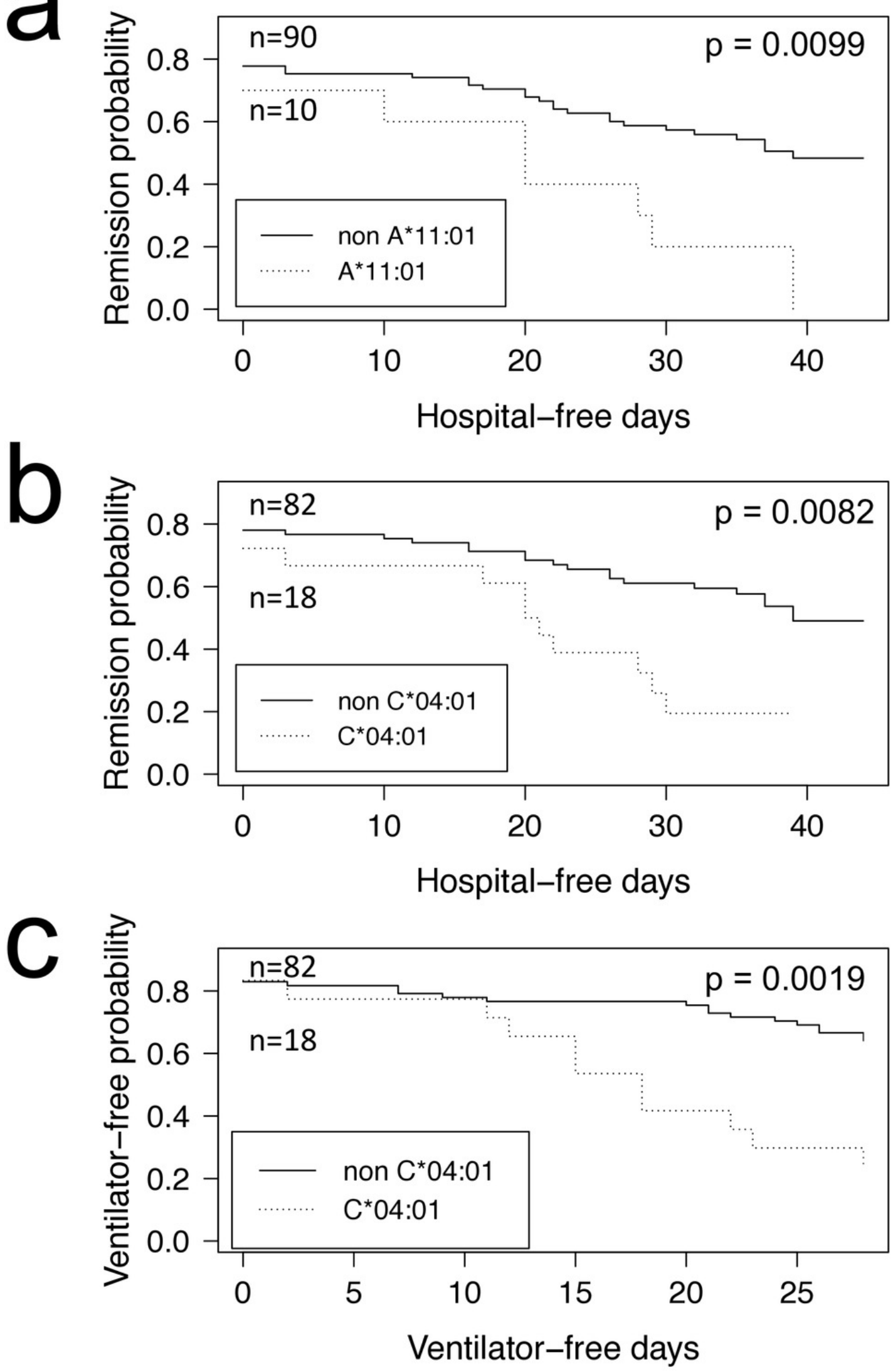


\section{Figure 2}

HLA alleles - demographics combinations with analytic (bottom) or prognostic (top) potential in a COVID-19 cohort.

We calculated the odds ratio (OR) for each HLA-I and HLA-II allele observed in $10 \%$ or more of patients, and plotted OR and the influence of demographics for HLA alleles showing significant associations (from Tables 1 and 2). First, looking at the influence of demographic characteristics such as sex (Female/Male), age (65 years old or above/less than 65 years old) and ethnicity (Minority/Non-minority [i.e. European ancestry]) on the susceptibility of patients with these alleles to test positive for COVID-19 (lower two panels), and on the risk associated with ICU hospitalization (upper two panels). Red asterisks indicate significant demographic characteristics at the alpha $=0.05$ level (Fisher's Exact Test) not corrected for multiple hypothesis tests. 

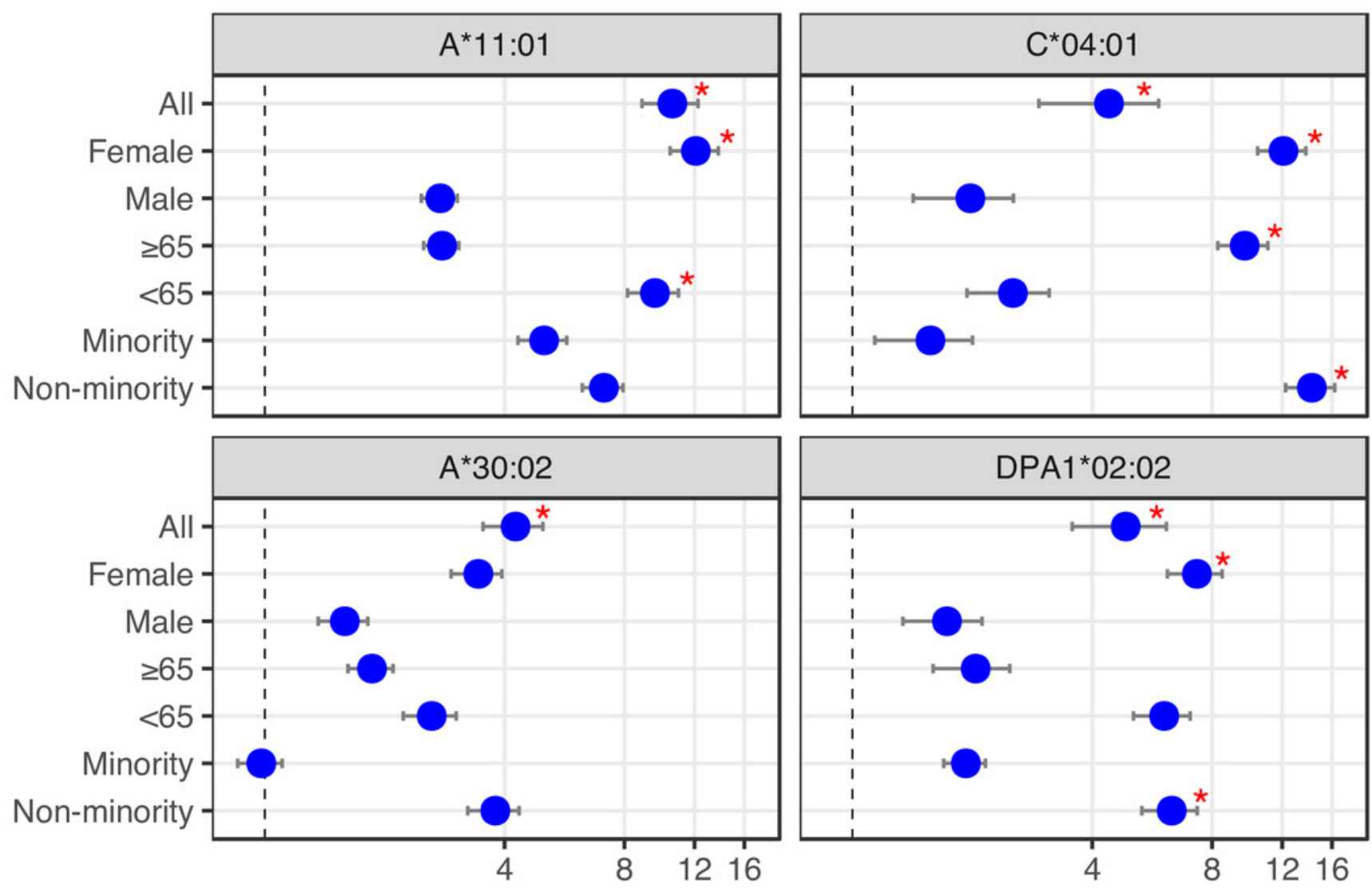

Odds ratio 


\section{Table $\mathbf{1}$ (on next page)}

HLA-I alleles identified in $10 \%$ or more COVID-19 positive patients and statistical tests of enrichment in the Overmyer et al. [27] COVID-19 positive (vs. negative) cohort and association with hospitalization.

Font in bold face indicates significant associations (Fisher's Exact Test) not corrected for multiple hypothesis tests. 
HLA-I COVID+ ICU- ICU+ COVIDpatients patients patients patients
H1: Bonferroni Enriched in COVID+

Fisher's Exact

Test $p$ value

\begin{tabular}{|c|c|c|c|c|c|c|c|c|}
\hline$A^{*} 02: 01$ & 30 & 15 & 15 & 12 & 0.9614 & 0.9614 & 0.5862 & 0.5862 \\
\hline$A * 24: 02$ & 23 & 12 & 11 & 6 & 0.6161 & 1 & 0.5000 & 1 \\
\hline$C^{*} 07: 02$ & 22 & 13 & 9 & 7 & 0.7890 & 1 & 0.8865 & 1 \\
\hline$C^{*} 07: 01$ & 18 & 12 & 6 & 7 & 0.8991 & 1 & 0.9668 & 1 \\
\hline$C * 04: 01$ & 18 & 4 & 14 & 3 & 0.3231 & 1 & 0.0087 & 0.0435 \\
\hline$C^{*} 06: 02$ & 16 & 8 & 8 & 6 & 0.8708 & 1 & 0.6071 & 1 \\
\hline$B * 51: 01$ & 16 & 10 & 6 & 2 & 0.2292 & 1 & 0.9143 & 1 \\
\hline$C^{*} 03: 04$ & 14 & 10 & 4 & 3 & 0.5171 & 1 & 0.9796 & 1 \\
\hline$C * 15: 02$ & 14 & 8 & 6 & 1 & 0.1363 & 1 & 0.8060 & 1 \\
\hline$A^{*} 01: 01$ & 13 & 8 & 5 & 7 & 0.9742 & 1 & 0.8832 & 1 \\
\hline$A^{*} 03: 01$ & 13 & 6 & 7 & 5 & 0.8680 & 1 & 0.5000 & 1 \\
\hline$A * 30: 02$ & 13 & 6 & 7 & 0 & 0.0417 & 0.5004 & 0.5000 & 1 \\
\hline$B^{*} 07: 02$ & 12 & 7 & 5 & 5 & 0.8969 & 1 & 0.8217 & 1 \\
\hline$A * 30: 01$ & 12 & 4 & 8 & 1 & 0.2016 & 1 & 0.1783 & 1 \\
\hline$B^{*} 44: 02$ & 11 & 7 & 4 & 4 & 0.8320 & 1 & 0.9001 & 1 \\
\hline$A^{*} 68: 01$ & 11 & 6 & 5 & 0 & 0.0697 & 1 & 0.7377 & 1 \\
\hline$A * 11: 01$ & 10 & 1 & 9 & 2 & 0.5320 & 1 & 0.0078 & 0.1326 \\
\hline
\end{tabular}

3

4

5 


\section{Table 2 (on next page)}

HLA-II alleles identified in 10\% or more COVID-19 positive patients and statistical tests of enrichment in the Overmyer et al. [27] COVID-19 positive (vs. negative) cohort and association with hospitalization.

Font in bold face indicates significant associations (Fisher's Exact Test) not corrected for multiple hypothesis tests. 
HLA-II COVID+ ICU- ICU+ COVID- H1: Bonferroni H1: Bonferroni patients patients patients patients Enriched correction Increased risk correction

Fisher's rank* Fisher's Exact abundance Exact Test $p$-value rank* $^{*}$

Test $\mathrm{p}$ value

\begin{tabular}{|c|c|c|c|c|c|c|c|c|}
\hline$D Q A 1{ }^{*} 01: 02$ & 52 & 23 & 29 & 13 & 0.5147 & 0.5147 & 0.1585 & 0.1585 \\
\hline$D P A 1^{*} 01: 03$ & 46 & 25 & 21 & 17 & 0.9769 & 1 & 0.8421 & 1 \\
\hline$D Q A 1^{*} 03: 02$ & 35 & 19 & 16 & 7 & 0.2971 & 0.8913 & 0.7991 & 1 \\
\hline DPA1*02:02 & 29 & 13 & 16 & 2 & 0.0174 & 0.0696 & 0.3299 & 1 \\
\hline$D P B 1 * 01: 01$ & 25 & 12 & 13 & 4 & 0.3701 & 1 & 0.5000 & 1 \\
\hline$D P B 1{ }^{*} 04: 01$ & 25 & 14 & 11 & 12 & 0.9959 & 1 & 0.8221 & 1 \\
\hline$D P A 1 * 02: 01$ & 22 & 11 & 11 & 6 & 0.6578 & 1 & 0.5952 & 1 \\
\hline$D P B 1{ }^{*} 02: 01$ & 21 & 12 & 9 & 3 & 0.2117 & 1 & 0.8369 & 1 \\
\hline$D Q A 1 * 05: 02$ & 20 & 10 & 10 & 3 & 0.2453 & 1 & 0.5984 & 1 \\
\hline$D Q A 1{ }^{*} 02: 01$ & 15 & 7 & 8 & 6 & 0.8967 & 1 & 0.5000 & 1 \\
\hline$D R B 1 * 07: 01$ & 15 & 7 & 8 & 3 & 0.8967 & 1 & 0.5000 & 1 \\
\hline$D Q B 1{ }^{*} 02: 01$ & 14 & 8 & 6 & 6 & 0.9192 & 1 & 0.8060 & 1 \\
\hline$D R B 1 * 15: 01$ & 14 & 8 & 6 & 3 & 0.7008 & 1 & 0.8060 & 1 \\
\hline$D Q B 1 * 03: 09$ & 13 & 8 & 5 & 1 & 0.1662 & 1 & 0.8832 & 1 \\
\hline$D P B 1 * 104: 01$ & 13 & 9 & 4 & 6 & 0.9385 & 1 & 0.9643 & 1 \\
\hline$D Q B 1 * 05: 01$ & 12 & 6 & 6 & 4 & 0.7913 & 1 & 0.6202 & 1 \\
\hline$D Q B 1{ }^{*} 06: 11$ & 11 & 5 & 6 & 3 & 0.6811 & 1 & 0.5000 & 1 \\
\hline$D P B 1 * 105: 01$ & 11 & 1 & 10 & 2 & 0.4712 & 1 & 0.0039 & 0.0702 \\
\hline$D R B 1 * 15: 02$ & 11 & 5 & 6 & 0 & 0.1804 & 1 & 0.5000 & 1 \\
\hline$D Q B 1 * 06: 02$ & 11 & 5 & 6 & 3 & 0.6811 & 1 & 0.5000 & 1 \\
\hline DRB1*13:01 & 11 & 4 & 7 & 4 & 0.8320 & 1 & 0.2623 & 1 \\
\hline$D Q A 1{ }^{*} 05: 01$ & 10 & 5 & 5 & 4 & 0.8689 & 1 & 0.6297 & 1 \\
\hline$D P B 1{ }^{*} 05: 01$ & 10 & 5 & 5 & 1 & 0.2912 & 1 & 0.6297 & 1 \\
\hline$D R B 1 * 11: 01$ & 10 & 4 & 6 & 5 & 0.9427 & 1 & 0.3703 & 1 \\
\hline$D P B 1 * 04: 02$ & 10 & 8 & 2 & 0 & 0.2200 & 1 & 0.9922 & 1 \\
\hline
\end{tabular}

